\section{JTI}

JOURNAL OF

TRAUMA AND INJURY

\title{
Diagnostic and Therapeutic
} Laparoscopy for Abdominal Trauma: A Single Surgeon's Experience at a Level I Trauma Center

\author{
Hancheol Jo, M.D., M.S., Dong Hun Kim, M.D., M.S. \\ Department of Trauma Surgery, Trauma Center, Dankook University Hospital, Cheonan, \\ Korea
}

Received: December 9, 2020

Revised: December 16, 2020

Accepted: January 20, 2021

\section{Correspondence to}

\section{Dong Hun Kim, M.D., M.S.}

Department of Trauma Surgery, Trauma Center, Dankook University Hospital, 201

Manghyang-ro, Dongnam-gu, Cheonan

31116 , Korea

Tel: +82-41-550-3042

Fax: +82-41-550-0039

E-mail: saint7331@gmail.com

ORCID: https://orcid.org/0000-0001-

6613-6902 http://www.jtraumainj.org
Purpose: Laparoscopy has various advantages over laparotomy in terms of postoperative recovery. The number of surgeons using laparoscopy as a diagnostic and therapeutic tool in abdominal trauma patients is increasing, whereas open conversion is becoming less common. This report summarizes a single surgeon's experience of laparoscopy at a level I trauma center and evaluates the feasibility of laparoscopy as a diagnostic and therapeutic tool for abdominal trauma patients.

Methods: In total, 30 abdominal trauma patients underwent laparoscopy by a single surgeon from October 2014 to May 2020. The purpose of laparoscopy was categorized as diagnostic or therapeutic. Patients were classified into three groups by type of surgery: total laparoscopic surgery (TLS), laparoscopy-assisted surgery (LAS), or open conversion (OC). Univariate analysis was performed to determine the advantages and disadvantages.

Results: The mechanism of injury was blunt in $19(63.3 \%)$ and penetrating in 11 patients (36.7\%). Eleven (36.7\%) and 19 patients (63.3\%) underwent diagnostic and therapeutic laparoscopy, respectively. The hospital stay was shorter for patients who underwent diagnostic laparoscopy than for those who underwent therapeutic laparoscopy (5.0 days vs. 13.0 days), but no other surgical outcomes differed between the groups. TLS, LAS, and OC were performed in 12 (52.2\%), eight (34.8\%), and three patients (13.0\%), respectively. There was no significant difference in morbidity and mortality among the three groups.

Conclusions: Laparoscopic surgery for selected cases of abdominal trauma may be feasible and safe as a diagnostic and therapeutic tool in hemodynamically stable patients due to the low $\mathrm{OC}$ rate and the absence of fatal morbidity and mortality.

Keywords: Laparoscopy; Abdominal injuries; Wounds, penetrating; Wounds, nonpenetrating; Laparotomy

\section{Copyright $(2021$ The Korean Society of Traumatology}

This is an Open Access article distributed under the terms of the Creative Commons Attribution Non-Commercial License (http://creativecommons.org/licenses/by-nc/4.0/) which permits unrestricted noncommercial use, distribution, and reproduction in any medium, provided the original work is properly cited. 


\section{INTRODUCTION}

Laparoscopy has various advantages over laparotomy in terms of postoperative recovery. As surgeons' overall experience and skills develop, laparoscopy is increasingly used in elective surgery and acute care surgery. However, laparoscopy has not been widely used in abdominal trauma patients because it could be considered only in hemodynamically stable patients, especially since the probability of missed injuries is higher and the operative time is longer than that for open laparotomy $[1,2]$. Nevertheless, as laparoscopic surveillance has been shown to reduce the negative laparotomy rate [3], the number of surgeons using laparoscopy in abdominal trauma patients has increased and the number of cases of conversion to laparotomy has decreased $[4,5]$. Therefore, the current team of authors became interested in proving whether laparoscopy is suitable as a diagnostic and therapeutic tool in abdominal trauma patients. This report summarizes a single surgeon's 6 years of experience performing laparoscopy at a level I trauma center, and it evaluates the feasibility of laparoscopy as a diagnostic and therapeutic tool for abdominal trauma patients.

\section{METHODS}

Medical records for abdominal trauma patients who underwent laparoscopy by a single surgeon from October 2014 to May 2020 at a level I trauma center were retrospectively reviewed. The informed consent was waived from Institutional Review Board due to the retrospective study design. Since there was no consensus regarding the indications for laparoscopy in abdominal trauma patients among several trauma surgeons at this center, only laparoscopic procedures performed by a single experienced surgeon were analyzed to ensure the consistency of outcomes. The main eligibility criteria for laparoscopy were hemodynamic stability and systolic blood pressure $>90$ $\mathrm{mmHg}$ without vasopressor infusion. Table 1 presents the complete inclusion and exclusion criteria for this study.

The purpose of laparoscopy was categorized as either diagnostic or therapeutic. Diagnostic laparoscopy was performed to diagnose an injury if there was a discrep- ancy between positive findings on a clinical examination and negative findings on imaging studies. Therapeutic laparoscopy included various surgical procedures for the treatment of an already-diagnosed injury. The study focused on whether treatment outcomes differed between diagnostic and therapeutic laparoscopy.

Patients were classified into three groups according to the use of laparoscopy during surgery: total laparoscopic surgery (TLS), laparoscopy-assisted surgery (LAS), and open conversion (OC). TLS was defined as the diagnosis of an injury and therapeutic procedure performed only with the laparoscopic approach. LAS was defined as laparoscopic focusing of the injury and extracorporeal resection or repair performed with an additional laparotomy incision ( $\leq 10 \mathrm{~cm}$ long) due to the difficulty of therapeutic laparoscopy, followed by reorganization with laparoscopy again. OC was defined as an intraoperative change of approach from laparoscopy to a main laparotomy incision. The study focused on the factors determining the type of surgery and whether treatment outcomes differed based on the type of surgery. Univariate analysis was performed among the three patient groups based on the type of surgery: TLS (except for exploration and simple closure, i.e., diagnostic laparoscopy), LAS, and OC.

\section{Data collection}

The collected data included patients' demographic characteristics and various clinical notes such as the type of injury, hemodynamic status and laboratory data on admission, indication for surgery, operative findings, type

Table 1. Inclusion and exclusion criteria

\begin{tabular}{|c|c|}
\hline Inclusion criteria & Exclusion criteria \\
\hline $\begin{array}{l}\text { Hemodynamically stable } \\
\text { patients }\end{array}$ & Age $<18$ or $>65$ years \\
\hline $\begin{array}{l}\text { SBP }>90 \mathrm{mmHg} \text {, without } \\
\text { vasopressor infusion }\end{array}$ & Traumatic brain injury \\
\hline Definitive hollow viscus injury & $\begin{array}{l}\text { Chest injuries with massive hemotho- } \\
\text { rax or severe lung contusion }\end{array}$ \\
\hline Intraperitoneal bladder rupture & Emergency concerrent operation \\
\hline $\begin{array}{l}\text { Hemoperitoneum without } \\
\text { massive transfusion }\end{array}$ & $\begin{array}{l}\text { Peripheral vascular injury requiring } \\
\text { operation }\end{array}$ \\
\hline
\end{tabular}

SBP: systolic blood pressure. 
of surgery, therapeutic procedures, Injury Severity Score (ISS), abdominal Abbreviated Injury Scale (AIS), and treatment outcomes. The treatment outcomes included hospital stay, the day that postoperative oral intake (sips of water and soft diet) started, the day that the Jackson-Pratt drain was removed, the units of red blood cell transfusion, operation time, estimated blood loss (EBL), and complications.

\section{Laparoscopic techniques}

First, a 12-mm trocar was inserted through an umbilical incision, and then carbon dioxide was injected to create pneumoperitoneum at a pressure of $12 \mathrm{mmHg}$. A $45^{\circ}$ angle, 10-mm laparoscope was primarily used, and 2 to 4 working ports were inserted as necessary. The peritoneal cavity was explored to check the presence of bowel contents and for hematoma. Exploration was also performed for solid organ damage, such as to the liver and spleen, and damage to the hollow viscus from the esophagogastric junction, through the stomach and small bowel to the ileocecal valve, and finally to the colon and rectum, in that order.

\section{Statistical analysis}

All statistical analyses used the software environment $\mathrm{R}$ (version 3.6.1, Comprehensive R Archive Network; http:// cran.r-project.org), expressing group variables as median (25-75th percentile). The Mann-Whitney $U$ test was used to analyze independent samples of continuous variables, whereas the Fisher exact test was used for categorical values. The Kruskal-Wallis test was used to analyze differences among $\geq 3$ groups. Statistical significance was set at $p<0.05$.

\section{RESULTS}

\section{Patient demographics}

Of the 30 abdominal trauma patients who underwent laparoscopy, 20 patients $(66.7 \%)$ were male. The median age was $46.5(31.0-58.3)$ years. Body mass index was 22.9 $(21.0-26.8) \mathrm{kg} / \mathrm{m}^{2}$, and the American Society of Anesthesiologists score was 2.0 (2.0-3.0). Three-dimensional laparoscopy was performed for five patients (16.7\%). Pre- operative systolic blood pressure was 129.5 (114.3-144.3) mmHg; the pulse rate was 86.5 (74.3-101.0) bpm; the respiratory rate was $18.0(17.0-20.0)$ breaths/minute; the Glasgow Coma Scale score was 15.0 (15.0-15.0), and hemoglobin level was 13.8 (12.3-14.8) g/dL on arrival. The mechanism of injury was blunt trauma in 19 patients $(63.3 \%)$ and penetrating trauma in 11 patients (36.7\%). The most common cause of trauma was an in-car traffic accident (TA) in 11 patients (36.7\%), followed by a stab injury in $10(33.3 \%)$, a pedestrian TA in four (13.3\%), blunt abdominal trauma due to impacts by any object in three $(10.0 \%)$, and a motorcycle TA in two (6.7\%) (Table 2). Upon admission, 28 patients (93.3\%) described abdominal pain and two (6.7\%) did not report any specific symptoms in the abdomen.

Eighteen patients $(60.0 \%)$ had a hollow viscus injury

Table 2. Patient characteristics

\begin{tabular}{|lc|}
\hline & Value $(\mathbf{n}=30)$ \\
\hline Male patients & $20(66.7)$ \\
\hline Age (years) & $46.5(31.0-58.3)$ \\
BMl & $22.9(21.0-26.8)$ \\
ASA score & $2.0(2.0-3.0)$ \\
3D laparoscopy & $5(16.7)$ \\
SBP (mmHg) & $129.5(114.3-144.3)$ \\
Pulse rate (BPM) & $86.5(74.3-101.0)$ \\
Respiratory rate (breaths/min) & $18.0(17.0-20.0)$ \\
GCS score & $15.0(15.0-15.0)$ \\
Hemoglobin (g/dL) & $13.8(12.3-14.8)$ \\
Mechanism of injury & \\
Blunt & $19(63.3)$ \\
Penetrating & $11(36.7)$ \\
Causes of trauma & \\
In-car-TA & $11(36.7)$ \\
Stab injury & $10(33.3)$ \\
Pedestrian TA & $4(13.3)$ \\
Blunt abdominal trauma impacted by any & $3(10.0)$ \\
object & $2(6.7)$ \\
Motorcycle TA & \\
\hline
\end{tabular}

Values are presented as number (\%) or median (interquartile range). BMI: body mass index, ASA: American Society of Anesthesiologists, 3D: three-dimensional, SBP: systolic blood pressure, BPM: beats per minute, GCS: Glasgow Coma Scale, TA: traffic accident. 
and seven $(23.3 \%)$ had a solid organ injury. Among the patients with hollow viscus injury and solid organ injury, the most common site of each injury was the jejunum, in nine patients $(50.0 \%)$, and the liver, in three patients (42.9\%) (Table 3$)$. The most common abdominal AIS score was 3 points, for 14 patients (46.7\%), followed by 11 patients $(36.7 \%)$ with 2 points, three $(10.0 \%)$ with 1 point, and one $(3.3 \%)$ each with 4 points and 0 points. None of the patients had a score of either 5 or 6 points. The median ISS was $9.0(4.0-15.5)$.

\section{Surgical procedures}

The number of working laparoscopy ports was 2.0 (2.0 $2.0)$, with $2.0(2.0-2.0)$ in the diagnostic group and 2.0 $(2.0-2.5)$ in the therapeutic group. There was no significant difference in the number of laparoscopic ports between the two groups $(p=0.657)$. In the diagnostic group, seven patients $(23.3 \%)$ received only exploration and simple closure. In the therapeutic group, injury repair was performed for 15 patients (50\%), resection in 11 (36.7\%), and vessel ligation in two (6.7\%) (Table 4). Except for seven patients who underwent only exploration and simple closure, TLS was performed in 12 (52.2\%), LAS in eight

Table 3. Diagnosis of injured organs in the operative field

\begin{tabular}{|lc|}
\hline & Value \\
\hline Hollow viscus injury & $18(60.0)$ \\
Jejunum & $9(30.0)$ \\
Transverse colon & $4(13.3)$ \\
Bladder & $3(10.0)$ \\
Stomach & $2(6.7)$ \\
Duodenum & $1(3.3)$ \\
Descending colon & $1(3.3)$ \\
Solid organ injury & $1(3.3)$ \\
Liver & $7(23.3)$ \\
Spleen & $3(10.0)$ \\
Omentum & $2(6.7)$ \\
Pancreas & $2(6.7)$ \\
Gallbladder & $1(3.3)$ \\
Only abdominal wall injury & $1(3.3)$ \\
\hline
\end{tabular}

Values are presented as number (\%).
(34.8\%), and OC in three patients (13.0\%). The conversion rate for open laparotomy was $13.0 \%$ among the total of 23 patients who underwent therapeutic surgery. The reasons for performing open laparotomy conversion were difficulty of visualization due to bleeding in two cases and difficulty of mobilization in one case.

\section{Treatment outcomes}

The hospital stay was 8.5 (5.0-17.3) days. Sips of water were allowed for patients after 2.0 (1.0-2.0) days, and a soft diet was allowed for patients after 3.0 (2.0-4.0) days postoperatively. Blood transfusion was not performed in 21 patients $(70.0 \%)$, while nine $(30.0 \%)$ received a blood transfusion in the perioperative period. The amount of blood transfusion was 6.0 (2.0-8.0) units, calculated only for red blood cells. A Jackson-Pratt drain was installed in

Table 4. Surgical procedures in therapeutic laparoscopy

\begin{tabular}{|ll|}
\hline \multicolumn{2}{|l|}{ Value } \\
\hline Rotal laparoscopic & \\
Small bowel & $6(20.0)$ \\
Bladder & $2(6.7)$ \\
Stomach & $1(3.3)$ \\
Colon & $1(3.3)$ \\
Resection of & \\
Omentum & $4(13.3)$ \\
Small bowel & $2(6.7)$ \\
Appendix & $1(3.3)$ \\
Vessel ligation of omentum & $1(3.3)$ \\
Colostomy & $1(3.3)$ \\
Laparoscopy-assisted & \\
Repair of & \\
Small bowel & \\
Colon & \\
Resection of & $3(10.0)$ \\
Small bowel & $2(6.7)$ \\
Appendix & $1(3.3)$ \\
Open conversion & \\
Resection of spleen & $1(3.3)$ \\
\hline
\end{tabular}

Values are presented as number (\%). 
19 patients $(63.3 \%)$, and drain removal occurred at 5.0 (4.0-6.0) days after surgery. The operation time was 147.5 (106.3-181.5) minutes, and the EBL was 100.0 (50.0500.0) $\mathrm{mL}$.

Complications occurred in five patients (16.7\%) postoperatively: one patient with postoperative bleeding was treated with laparoscopic reoperation; one patient with intraperitoneal fluid collection was drained by percutaneous catheter insertion, and one patient each with wound seroma, acute respiratory distress syndrome, and pancreatic pseudocyst recovered with supportive care. No injuries were missed, and no mortality occurred among the 30 patients.

The flowchart of laparoscopic surgery is summarized in Fig. 1. Of the 11 patients (36.7\%) who underwent diagnostic laparoscopy, four $(36.4 \%)$ were treated for the injuries revealed in the operative field, whereas 19 (63.3\%) underwent therapeutic laparoscopy based on the initial indication. The hospital stay, operation time, and postoperative diet were significantly shorter and earlier in the di- agnostic laparoscopy group than in the therapeutic group. However, there was no significant difference between the two groups in perioperative transfusions and complications (Table 5).

The patients who underwent TLS (except seven patients who underwent exploration and simple closure) started a soft diet on postoperative day 3 (2.0-3.3), significantly earlier than those who were treated with LAS according to the Mann-Whitney $U$ test $(p=0.016)$. There was no significant difference in the postoperative day of starting a soft diet between the TLS and OC groups $(p=0.259)$ and between the LAS and OC groups $(p=0.528)$. No differences in the hospital stay, perioperative transfusion units, or other factors among the three groups were shown in the univariate analysis (Table 6).

\section{DISCUSSION}

Trauma surgeons should not hesitate to perform laparos-

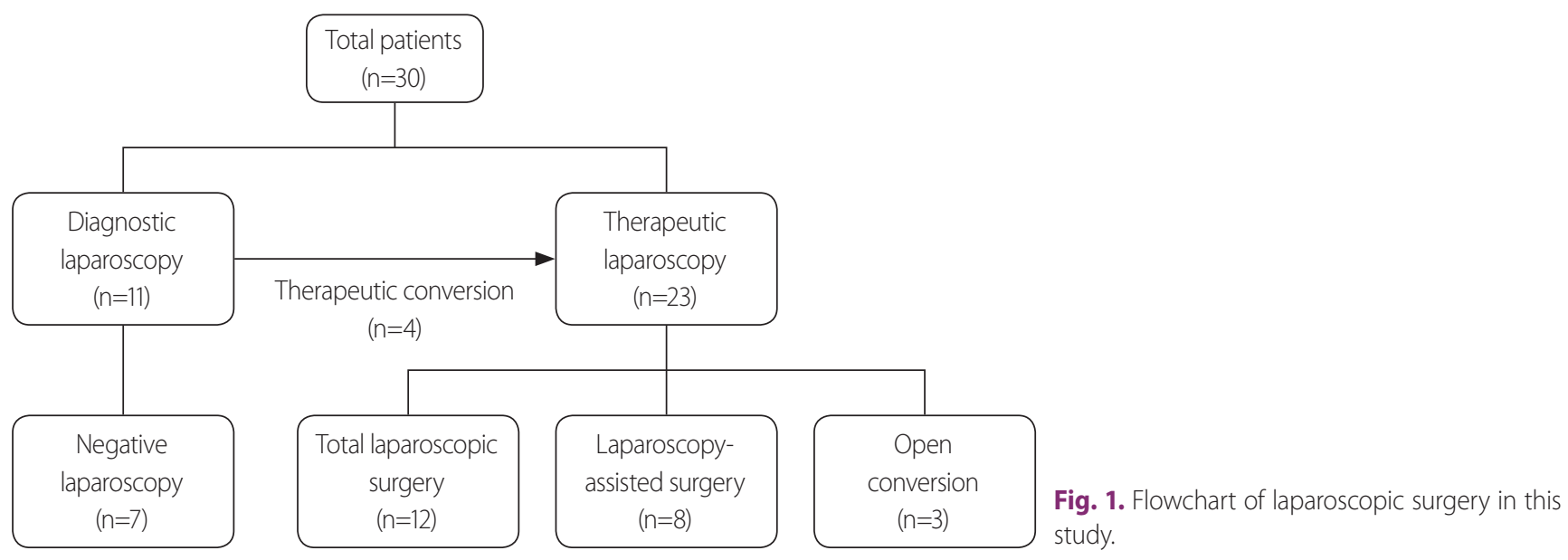

Table 5. Outcomes among patients grouped by indication for laparoscopy

\begin{tabular}{|c|c|c|c|}
\hline & Diagnostic laparoscopy $(n=11)$ & Therapeutic laparoscopy $(n=19)$ & $p$-value \\
\hline Hospital stay (day) & $5.0(3.5-7.0)$ & $13.0(7.5-25.5)$ & 0.002 \\
\hline Perioperative RBC transfusion (unit) & $0(0.0-0.0)$ & $0(0.0-3.0)$ & 0.075 \\
\hline Postoperative diet (day) & $1.0(1.0-2.0)$ & $3.0(3.0-5.0)$ & 0.000 \\
\hline Operation time (min) & $105.0(67.5-117.5)$ & $165.0(140.0-210.0)$ & 0.002 \\
\hline Morbidity & $0(0.0)$ & $5(26.3)$ & 0.129 \\
\hline
\end{tabular}

Values are presented as number (\%) or median (interquartile range). 
Table 6. Univariate analysis among patients grouped by surgery type

\begin{tabular}{|c|c|c|c|c|}
\hline & $\begin{array}{l}\text { Total laparoscopic surgery } \\
\qquad(n=12)\end{array}$ & $\begin{array}{l}\text { Laparoscopy-assisted surgery } \\
\qquad(\mathrm{n}=8)\end{array}$ & Open conversion $(n=3)$ & $p$-value \\
\hline Age (years) & $51.0(43.8-61.0)$ & $38.5(30.5-44.8)$ & $52.0(37.5-58.5)$ & 0.547 \\
\hline Sex & & & & 0.817 \\
\hline Male & $8(66.7)$ & $6(75.0)$ & $3(100)$ & \\
\hline Female & $4(33.3)$ & $2(25.0)$ & $0(0.0)$ & \\
\hline $\mathrm{BMl}$ & $24.10(21.53-26.36)$ & 21.51 (20.89-25.10) & $24.06(22.06-25.70)$ & 0.663 \\
\hline ISS & $11.0(4.0-18.0)$ & $11.5(9.0-22.0)$ & $8.0(6.0-12.0)$ & 0.545 \\
\hline $\mathrm{SBP}(\mathrm{mmHg})$ & 134.5 (105.25-139.0) & 118.5 (114.75-133.0) & $152.0(148.50-154.50)$ & 0.173 \\
\hline $\mathrm{pH}$ & $7.38(7.36-7.43)$ & $7.41(7.36-7.43)$ & $7.41(7.32-7.41)$ & 0.739 \\
\hline Base excess & $-1.50(-4.52$ to -0.70$)$ & $-0.15(-1.95$ to 0.60$)$ & $-0.90(-8.65$ to -0.60$)$ & 0.342 \\
\hline Lactate (g/dL) & $2.55(1.75-3.92)$ & $1.85(1.27-3.25)$ & $1.40(1.20-6.70)$ & 0.773 \\
\hline SOFA score & $0.0(0.0-1.5)$ & $1.0(0.0-2.5)$ & $3.0(1.5-6.5)$ & 0.405 \\
\hline Operation time (min) & $145.0(103.25-179.75)$ & 167.5 (141.25-198.75) & $210.0(180.0-210.0)$ & 0.450 \\
\hline $\mathrm{EBL}(\mathrm{mL})$ & $75.0(20.0-187.50)$ & $200.0(87.50-372.50)$ & $1,500.0(1,000.0-1,750.0)$ & 0.081 \\
\hline Hospital stay (day) & $11.0(5.0-22.3)$ & $9.5(8.0-13.0)$ & $12.0(9.5-26.5)$ & 0.847 \\
\hline RBC transfusion (unit) & $0(0.0-0.3)$ & $1.0(0.0-4.5)$ & $2.0(1.0-4.0)$ & 0.485 \\
\hline Postoperative diet (day) & $3.0(2.0-3.3)$ & $4.5(3.8-5.5)$ & $3.0(3.0-5.0)$ & 0.039 \\
\hline Drain removal (day) & $3.5(0.0-6.0)$ & $4.5(4.0-5.3)$ & $9.0(7.0-11.0)$ & 0.115 \\
\hline Morbidity & $2(16.7)$ & $1(12.5)$ & $2(66.7)$ & 0.208 \\
\hline Mortality & $0(0.0)$ & $0(0.0)$ & $0(0.0)$ & - \\
\hline
\end{tabular}

Values are presented as number (\%) or median (interquartile range).

BMI: body mass index, ISS: injury severity score, SBP: systolic blood pressure, SOFA: sequential organ failure assessment, EBL: estimated blood loss, RBC: red blood cell.

copy for diagnostic reasons, and once an injury is revealed in the operative field, it can be treated with laparoscopy or OC, depending on the degree of injury. In patients with abdominal trauma, laparoscopy as a diagnostic tool is commonly considered an option today. It is important to find potential injuries as soon as possible, but a physical examination alone is often insufficient for diagnosis. In patients with penetrating trauma, local wound exploration has been performed to determine whether peritoneal penetration occurred; however, because of the possibility of false-negative results and wound contamination, this approach is not commonly used [6]. Diagnostic peritoneal lavage (DPL) is cost-effective, easy to perform, and has a sensitivity of $98 \%$, so it has been widely used. However, the specificity of DPL is relatively low, which can lead to unnecessary exploratory operations [7]. Focused assessment with sonography for trauma and computed tomog- raphy are widely used as noninvasive screening tools and diagnostic modalities with high sensitivity and specificity. However, despite the development of these diagnostic imaging modalities, many cases do not clearly align with any indications for nonoperative management or urgent laparotomy [8]. Against this background, several surgical guidelines [9-12] recommend performing laparoscopy as a screening, diagnostic, and therapeutic tool for selected patients with blunt and penetrating abdominal trauma. This study showed that patients who initially received diagnostic laparoscopy had shorter hospital stay and operation time, and an earlier postoperative start of a soft diet, than those treated with therapeutic laparoscopy. In patients who underwent diagnostic laparoscopy, no transfusion was required, and there were no complications. In addition, none of the patients who underwent exploration and simple closure with initially planned diagnostic lapa- 
roscopy experienced any complications or missed injuries.

The criteria for laparoscopy are hemodynamic stability, absence of intracranial trauma, and absence of an indication for urgent laparotomy. Although studies have reported that laparoscopy was performed despite hemodynamic instability, this condition is generally considered a contraindication to laparoscopy $[1,2]$. When an intracranial injury is suspected, laparoscopy should be carefully performed because intra-abdominal pressure increases due to pneumoperitoneum, which in turn may result in an increase in intracranial pressure [13]. According to several previous studies $[8,14,15]$, several indications exist for laparoscopy as a diagnostic and therapeutic tool for patients with blunt and penetrating abdominal trauma, as follows: worrisome clinical signs and symptoms (e.g., evidence of peritoneal irritation, tachycardia, and leukocytosis), suspected hollow viscus or diaphragmatic injury, free fluid of unknown source or suspected mesenteric laceration, a significant amount of free fluid and unclear bleeding status (ongoing or stopped spontaneously) with suspected solid organ injury, a significant discrepancy between the results of clinical examination and imaging studies, and hemodynamic stability in penetrating trauma. The findings of the present study are similar to those of previous studies in that hemodynamic stability of patients undergoing laparoscopy is mandatory. In contrast, several differences in selection criteria have been noted; for example, intraperitoneal bladder rupture was included as an indication for laparoscopy, whereas massive transfusion was an exclusion criterion in this study, even if the patient was hemodynamically stable.

Currently, laparoscopy can be performed despite diffuse peritonitis. In the past, peritonitis was considered a contraindication to laparoscopy based on the thought that malignant hypercapnia had occurred due to increased intraperitoneal pressure and that the procedure would create the potential for bacteria and toxins to enter the bloodstream and increase carbon dioxide absorption. Other factors suggesting caution in the choice of laparoscopy were difficulty securing vision and manipulating the instruments due to intestinal edema caused by traumatic peritonitis. However, because edema worsens over time, it is important to perform laparoscopy as soon as possible after trauma. In addition, several studies [16-20] showed successful outcomes with laparoscopy as a treatment for duodenal or colonic perforation and perforated peptic ulcer. In the cases analyzed in this study, laparoscopy was performed despite diffuse peritonitis. Six patients with generalized peritonitis were treated with TLS or LAS; among them, five patients recovered without complications, but one patient had postoperative intra-abdominal fluid collection drained by percutaneous catheter insertion. In short, the indications for laparoscopy in abdominal trauma patients have not yet been standardized, and they vary depending on the skill of each surgeon and the setting of the trauma center.

If possible, TLS may be a better choice to treat abdominal trauma for several reasons. Laparoscopy has the advantage of a shorter hospital stay compared with open laparotomy [21-24]. In addition, in the present study, the patient group who underwent TLS started a soft diet earlier than those who underwent LAS. Although the OC group seemed to start a soft diet early, the difference might not be of clinical significance due to the small sample size of the OC group. The conversion rate to open laparotomy has been reported to range from $2.1 \%$ to $45 \%$ in penetrating trauma and from $8.5 \%$ to $50 \%$ in blunt trauma $[22,23,25,26]$ across many trauma centers, depending on surgeons' propensity to convert the procedure. An important point to consider is that it is necessary to perform surgery with clear criteria for conversion. In this current study, multiple univariate analyses were performed to determine the factors affecting OC, but no clear and significant findings were evident.

Sufficient surgical skill is necessary to determine a negative laparoscopy, and the laparoscopic procedure and approach must be chosen to prevent any missed injuries. In the past, laparoscopy was considered to have a high probability of missed injury in abdominal trauma patients. Furthermore, due to the possibility that a small bowel injury might not be detected, many surgeons hesitate to perform laparoscopy [5]. However, according to the studies of Choi [4] and Kawahara et al. [27], systematized laparoscopic exploration was established to eliminate the probability of missed injury. In addition, the number of skillful trauma surgeons should be sufficient to actively apply laparoscopy to the diagnosis and treatment of trauma patients. However, the number of trauma surgeons 
remains insufficient, and existing training programs are poor. Therefore, it is necessary to establish training programs to teach laparoscopic skills to trauma surgeons.

This study has several limitations. It is a retrospective study and has a small sample size. The lack of a large sample size may have led to inaccurate measurements of the surgeon's skill due to discrepancies among surgeons regarding their laparoscopic experience, and the complication rate among the patient groups may also be unclear.

\section{CONCLUSION}

Laparoscopic surgery for selected cases of abdominal trauma may be feasible and safe as a diagnostic and therapeutic tool in hemodynamically stable patients due to the low OC rate and absence of serious morbidity and mortality. Moreover, trauma surgeons should not hesitate to perform laparoscopy for diagnostic reasons because diagnostic laparoscopy results in a shorter hospital stay and operation time, and earlier postoperative diet, than therapeutic laparoscopy. Future research is needed to determine the indications for converting to laparotomy during laparoscopic surgery.

\section{CONFLICTS OF INTEREST}

No potential conflict of interest relevant to this article was reported.

\section{INFORMED CONSENT}

This type of study does not require informed consent.

\section{REFERENCES}

1. Goettler CE, Bard MR, Toschlog EA. Laparoscopy in trauma. Curr Surg 2004;61:554-9.

2. Uranues SF, A. Trauma laparotomy: indications, priorities, and damage control. In: Oestern H, Trentz OL, Uranues S, eds. Head, thoracic, abdominal, and vascular injuries: trauma surgery I.
Berlin:Springer;2011:333-42

3. Chol YB, Lim KS. Therapeutic laparoscopy for abdominal trauma. Surg Endosc 2003;17:421-7.

4. Choi GS. Systematized laparoscopic surgery in abdominal trauma. J Korean Surg Soc 1998;54:492-500.

5. Villavicencio RT, Aucar JA. Analysis of laparoscopy in trauma. J Am Coll Surg 1999;189:11-20.

6. Rosenthal RE, Smith J, Walls RM, Chen H, Kline PP, Shesser RF, et al. Stab wounds to the abdomen: failure of blunt probing to predict peritoneal penetration. Ann Emerg Med 1987;16:172-4.

7. Wood D, Berci G, Morgenstern L, Paz-Partlow M. Mini-laparoscopy in blunt abdominal trauma. Surg Endosc 1988;2:184-9.

8. Ozkan OV, Justin V, Fingerhut A, Uranues S. Laparoscopy in abdominal trauma. Current Trauma Reports 2016;2:238-46.

9. Hori Y; SAGES Guidelines Committee. Diagnostic laparoscopy guidelines : this guideline was prepared by the SAGES Guidelines Committee and reviewed and approved by the Board of Governors of the Society of American Gastrointestinal and Endoscopic Surgeons (SAGES), November 2007. Surg Endosc 2008;22:1353-83.

10. Agresta F, Ansaloni L, Baiocchi GL, Bergamini C, Campanile FC, Carlucci M, et al. Laparoscopic approach to acute abdomen from the Consensus Development Conference of the Società Italiana di Chirurgia Endoscopica e nuove tecnologie (SICE), Associazione Chirurghi Ospedalieri Italiani (ACOI), Società Italiana di Chirurgia (SIC), Società Italiana di Chirurgia d'Urgenza e del Trauma (SICUT), Società Italiana di Chirurgia nell'Ospedalità Privata (SICOP), and the European Association for Endoscopic Surgery (EAES). Surg Endosc 2012;26:2134-64.

11. Como JJ, Bokhari F, Chiu WC, Duane TM, Holevar MR, Tandoh MA, et al. Practice management guidelines for selective nonoperative management of penetrating abdominal trauma. J Trauma 2010;68:721-33.

12. Redmond HP, Andrews E, Hill DK. Diagnostic laparoscopy - clinical guidelines [Internet]. Dublin: Royal College of Surgeons in Ireland 2005 [cited 2005 Jul 1]. Available from: https:/www.researchgate.net/profile/Emmet-Andrews/publication/254644313_Diagnostic_Laparscopy_Clinical_Guidelines/ links/55782e8408aeb6d8c01e72c7/Diagnostic-Laparscopy-Clinical-Guidelines.pdf.

13. Kamine TH, Elmadhun NY, Kasper EM, Papavassiliou E, Schneider BE. Abdominal insufflation for laparoscopy increases intracranial and intrathoracic pressure in human subjects. Surg Endosc 2016;30:4029-32. 
14. Lim KH, Chung BS, Kim JY, Kim SS. Laparoscopic surgery in abdominal trauma: a single center review of a 7-year experience. World J Emerg Surg 2015;10:16.

15. Uranues S, Popa DE, Diaconescu B, Schrittwieser R. Laparoscopy in penetrating abdominal trauma. World J Surg 2015;39:1381-8.

16. Katkhouda N, Mouiel J. A new technique of surgical treatment of chronic duodenal ulcer without laparotomy by videocoelioscopy. Am J Surg 1991;161:361-4.

17. Regan MC, Boyle B, Stephens RB. Laparoscopic repair of colonic perforation occurring during colonoscopy. Br J Surg 1994;81:1073.

18. O’Sullivan GC, Murphy D, O’Brien MG, Ireland A. Laparoscopic management of generalized peritonitis due to perforated colonic diverticula. Am J Surg 1996;171:432-4.

19. Nathanson LK, Easter DW, Cuschieri A. Laparoscopic repair/ peritoneal toilet of perforated duodenal ulcer. Surg Endosc 1990;4:232-3.

20. Mouret P, François Y, Vignal J, Barth X, Lombard-Platet R. Laparoscopic treatment of perforated peptic ulcer. Br J Surg 1990;77:1006.

21. Sosa JL, Baker M, Puente I, Sims D, Sleeman D, Ginzburg E, et al. Negative laparotomy in abdominal gunshot wounds: potential impact of laparoscopy. J Trauma 1995;38:194-7.

22. Lin HF, Chen YD, Lin KL, Wu MC, Wu CY, Chen SC. Laparoscopy decreases the laparotomy rate for hemodynamically stable patients with blunt hollow viscus and mesenteric injuries. Am J Surg 2015;210:326-33.

23. Lin HF, Wu JM, Tu CC, Chen HA, Shih HC. Value of diagnostic and therapeutic laparoscopy for abdominal stab wounds. World J Surg 2010;34:1653-62.

24. Lee PC, Lo C, Wu JM, Lin KL, Lin HF, Ko WJ. Laparoscopy decreases the laparotomy rate in hemodynamically stable patients with blunt abdominal trauma. Surg Innov 2014;21:155-65.

25. Kaban GK, Novitsky YW, Perugini RA, Haveran L, Czerniach D, Kelly JJ, et al. Use of laparoscopy in evaluation and treatment of penetrating and blunt abdominal injuries. Surg Innov 2008;15:26-31.

26. Ahmed N, Whelan J, Brownlee J, Chari V, Chung R. The contribution of laparoscopy in evaluation of penetrating abdominal wounds. J Am Coll Surg 2005;201:213-6.

27. Kawahara NT, Alster C, Fujimura I, Poggetti RS, Birolini D. Standard examination system for laparoscopy in penetrating abdominal trauma. J Trauma 2009;67:589-95. 